\title{
Oxidative DNA damage accumulation in gastric carcinogenesis
}

\author{
F Farinati, R Cardin, P Degan, M Rugge, F Di Mario, P Bonvicini, R Naccarato
}

\begin{abstract}
Background-Gastric carcinogenesis is a multifactorial, multistep process, in which chronic inflammation plays a major role.

Aims-In order to ascertain whether free radical mediated oxidative DNA damage is involved in such a process, concentrations of 8-hydroxydeoxyguanosine (8OHdG), a mutagenic/carcinogenic adduct, and thiobarbituric acid reactive substances (TBARS), as an indirect measure of free radical mediated damage, were determined in biopsy specimens from patients undergoing endoscopy.
\end{abstract}

Patients-Eighty eight patients were divided into histological subgroups as follows: 27 with chronic non-atrophic gastritis, 41 with atrophic gastritis, six with gastric cancer, and 14 unaffected controls.

Methods-Intestinal metaplasia, Helicobacter pylori infection, and disease activity were semiquantitatively scored. 8OHdG concentrations were assessed by HPLC with electrochemical detection, and TBARS concentrations were fluorimetrically assayed.

Results-80HdG concentrations (mean number of adducts $/ 10^{5}$ dG residues) were significantly higher in chronic atrophic gastritis $(p=0.0009)$. Significantly higher concentrations were also detected in the presence of severe disease activity $(p=0.02)$, intestinal metaplasia $(p=0.035)$, and $H$ pylori infection $(\mathrm{p}=0.001)$. TBARS concentrations were also higher in atrophic gastritis, though not significantly so. In a multiple logistic regression analysis, 8OHdG concentrations correlated best with the presence and severity of $H$ pylori infection $(r=0.53, p=0.002)$.

Conclusions-Chronic gastritis is characterised by the accumulation of oxidative DNA damage with mutagenic and carcinogenic potential. $H$ pylori infection is the major determinant for DNA adduct formation.

(Gut 1998;42:351-356)

Keywords: free radicals; oxidative DNA damage; gastric carcinogenesis; precancerous changes; peroxidative damage

Correspondence to: Dr F Farinati, Cattedra Malattie Apparato Digerente, Istituto Medicina Interna, Policlinico Universitario, Via Giustiniani 2, 35128 Padova, Italy.

Accepted for publication 24 June 1997
Gastric carcinogenesis is a complex, multistep, and multifactorial event ${ }^{1}$ in which the role of Helicobacter pylori infection, the major aetiopathogenic factor for chronic antral gastritis and duodenal ulcer, has been established in the past few years. ${ }^{2-5}$ Current knowledge of the biological mechanisms underlying the lesions induced by this microorganism is still incomplete, however. For instance, the damage could be caused directly by $H$ pylori, through the release of cytotoxins, lipase, or phospholipase, or the urease mediated release of toxic ammonia ${ }^{6}{ }^{7}$ Alternatively, the damage could be due to the inflammatory reaction elicited by the microorganism. ${ }^{8}$ In the latter case, tissue damage and cell destruction by reactive oxygen species released by polymorphonuclear leucocytes might be involved. ${ }^{9}{ }^{10}$ This mechanism would also be important in terms of carcinogenesis, as free radical production may play a part in the multistep pathogenesis of both chronic gastric lesions and cancer. ${ }^{11}{ }^{12}$

Free radicals (or reactive oxygen species, ROS) are low molecular weight metabolites reactive enough to damage essential biological molecules, including nucleic acids. ${ }^{13}$ Indeed, many observations indicate that ROS have a causative role in carcinogenesis. During this process, ROS are known to interact directly with genomic $\mathrm{DNA}^{14}$; damage specific genes that control cell growth and differentiation during the initiation/promotion phase $^{15}$; increase the activity of carcinogenic xenobiotics ${ }^{16}$; and stimulate faster growth of malignant cells. ${ }^{17}$

A number of base modifications characteristic of hydroxyl radical injury have been confirmed, including thymine glycol, thymidine glycol, ${ }^{18}$ 5-hydroxyl-methyluracil, ${ }^{19}$ and 8-hydroxydeoxyguanosine $(8 \mathrm{OHdG}){ }^{20}$ All may cause point mutations in DNA by base substitution and can accumulate, but $8 \mathrm{OHdG}$ is considered to be the main DNA modification produced by $\mathrm{ROS}^{21}$; it is therefore used as an index of damage to the base sequence of DNA. $^{22}$

$H$ pylori related gastritis is characterised by increased free radical production and peroxidative damage. ${ }^{9324}$ We therefore investigated whether $H$ pylori infection was also related to a progressive accumulation of oxidative mutagenic/carcinogenic events that could play a major role in gastric carcinogenesis.

Materials and methods

PATIENT SELECTION AND ENDOSCOPIC PROCEDURES

The study involved 88 consecutive outpatients undergoing endoscopy for upper gastrointestinal symptoms. After giving their informed consent, patients provided information on their drinking and smoking habits and completed a food frequency questionnaire on their diet. Patients taking drugs capable of interfering 
with free radical production, such as nonsteroidal anti-inflammatory drugs, were excluded from the study.

Vitamin C intake was assessed on the basis of a record of the weighed weekly food intake, an accepted technique for assessing intake in population studies, which gives high correlations for vitamin $\mathrm{C}$ intake (expressed in $\mathrm{mg} /$ day) when all food is weighed for at least four days. ${ }^{25}$

At endoscopy, a $5 \mathrm{ml}$ gastric juice sample was aspirated for vitamin $\mathrm{C}$ determination. Routine endoscopy was then performed. Before withdrawal, biopsy specimens were taken from the antrum, incisura, and fundus $(2+2+2)$ for histological tests, and from the antrum $(2+1$ specimens) for $8 \mathrm{OHdG}$ and thiobarbituric acid reactive substances (TBARS) determination. Further biopsy specimens were also taken from any focal lesion.

\section{HISTOPATHOLOGY}

The biopsy specimens were examined for the presence of atrophy, ${ }^{26}$ disease activity (according to a semiquantitative score considering the extent of polymorphonuclear leucocyte and lymphocytic infiltration: $0=$ absent $+=\bmod -$ erate activity; $++=$ severe activity $\left.{ }^{26}\right)$, presence and extent of intestinal metaplasia $(0=$ absent; $+=$ mild, ranging from a few tubules to one third of the total area biopsied; $++=$ moderate/severe, ranging from one third to more than two thirds of the total area biopsied), presence and degree of epithelial dysplasia (according to Morson et al's criteria $^{27}$ ), and presence and extent of $H$ pylori colonisation (haematoxylin and eosin, modified Giemsa, immunostaining with monoclonal (Dako, Milan, Italy) antibody with a peroxidase antiperoxidase technique). Serum anti- $H$ pylori antibodies were not tested as the aim of the study was to assess the role of active infection.

The patients were grouped as follows: 27 with chronic non-atrophic gastritis ${ }^{26}$ (16 men, 11 women; mean age 53, range 25-83 years); 41 with chronic atrophic gastritis (30 men, 11 women; mean age 60 , range $41-78$ years); six with gastric cancer (five men, one woman, mean age 65 , range $44-81$ years); and 14 unaffected controls with no major or minor endoscopic or histological changes (eight men, six women; mean age 46 , range $25-74$ years). Twelve of the 41 patients with chronic atrophic gastritis also had mild epithelial dysplastic changes (seven men, five women; mean age 62 , range 37-74 years). Intestinal metaplasia was mild in $21 / 88$ patients and moderate/severe in 33/88. The number and percentage of $H$ pylori positive patients in the four groups were as follows: controls $0 / 14$, chronic non-atrophic gastritis 16/27 (59\%), chronic atrophic gastritis $24 / 41(58.5 \%)$, and gastric cancer $4 / 6(66 \%)$. A significant difference with respect to mean age $(p=0.01)$ was only found between controls and patients with chronic atrophic gastritis.
BIOCHEMICAL ANALYSES

Vitamin $C$

Immediately after sampling, aliquots of gastric juice were frozen in liquid nitrogen and analysed within three weeks, as vitamin C remains stable for this period of time.$^{28}$ In order to measure total ascorbic acid, any dehydroascorbic acid in the gastric juice samples was reduced to ascorbic acid using mercaptoethanol. After incubation for one hour at $20^{\circ} \mathrm{C}$ the reduction was nearly $100 \%$ and samples were prepared for HPLC by passing them through Sephadex G-100 columns (Pharmacia, Uppsala, Sweden). The recovery after purification was higher than $95 \%$. The purified samples were then analysed by ion pair chromatography in a $3 \mu \mathrm{m}$ C- 18 analytical column connected to a C-18 guard column (Supelco, Bellafonte, Pennsylvania, USA). Detection was by ultraviolet absorption at 267 $\mathrm{nm}$. Vitamin C concentrations were expressed in $\mu \mathrm{mol} / 1$.

Thiobarbituric acid reactive substances tissue concentrations

Antral biopsy specimens were taken from within $5 \mathrm{~cm}$ of the pylorus and were snap frozen in liquid nitrogen. Within two weeks, the samples were processed for TBARS, measured according to Masugi and Nakamura.$^{29}$ In brief, substances reacting with thiobarbituric acid were fluorimetrically quantified after homogenising the biopsy specimens in $50 \mathrm{mM}$ phosphate buffer at $\mathrm{pH}$ 7.4. TBARS tissue concentrations were expressed in $\mathrm{nmol} / \mathrm{g}$ tissue.

Quantification of $8 \mathrm{OHdG}$ in gastric mucosa DNA

Gastric biopsy specimens obtained at endoscopy were stored at $-80^{\circ} \mathrm{C}$ for up to three weeks, as we had previously obtained data (not shown) showing that storage under these conditions was unrelated to any alteration in results. After thawing, the specimens were homogenised in separation buffer $(75 \mathrm{mM}$ $\mathrm{NaCl} ; 10 \mathrm{mM}$ Tris/Cl pH 7.5; $5 \mathrm{mM}$ EDTA $\mathrm{pH} 6 ; 0.5 \%$ sodium dodecyl sulphate) and proteinase $\mathrm{K}$ at $55^{\circ} \mathrm{C}$ overnight. After treatment with ribonuclease A, the DNA was purified according to Fraga et al. ${ }^{30}$ Following nuclease P1 and alkaline phosphatase hydrolysis, samples were filtered through cellulose acetate Centricon filter units, $0.22 \mu \mathrm{m}$, and approximately $20 \mu \mathrm{g}$ DNA per sample was injected onto the HPLC column (Shimadzu, Kyoto, Japan).

The separation of $8 \mathrm{OHdG}$ and normal deoxynucleosides was performed in an LC18-DB (Supelco) column equipped with an LC-18-DB guard column cartridge. The solvent system consisted of an isocratic mixture of $90 \% 50 \mathrm{mM}$ potassium phosphate, $\mathrm{pH} 5.5$, and $10 \%$ methanol at a flow rate of $1 \mathrm{ml} / \mathrm{min}$. UV detection was accomplished at $254 \mathrm{~nm}$ and electrochemical analysis was done with a pulsed electrochemical detector (Dionex, Sunnyvale, California) in amperometric mode, with a glass-carbon electrode using an $\mathrm{Ag} / \mathrm{AgCl}$ reference electrode, at a voltage of $0.6 \mathrm{~V}$. The concentrations of $8 \mathrm{OHdG}$ were determined by 


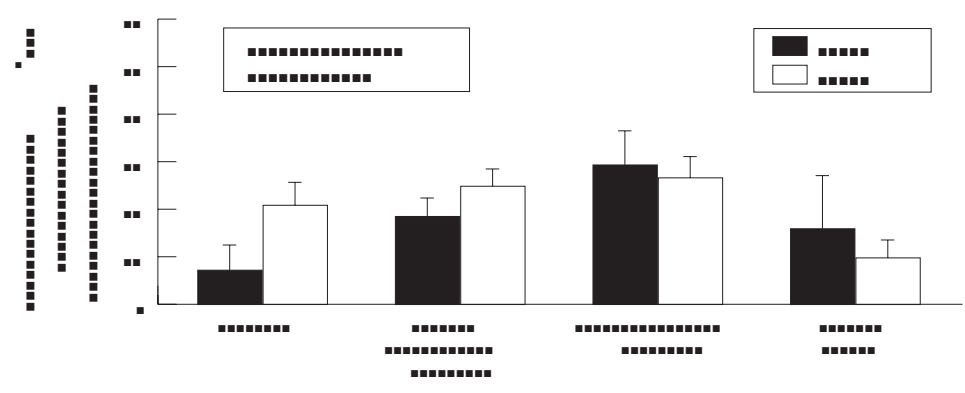

Figure 1 Mean (SEM) concentrations of $80 H d G$ and TBARS in gastric mucosa.

the amount of deoxyguanosine $(\mathrm{dG})$ detected by UV absorbency at $254 \mathrm{~nm}$. The amount of DNA was determined by a calibration curve constructed following measurement of known amounts of calf thymus DNA. The concentrations of $8 \mathrm{OHdG}$ were expressed as the number of $8 \mathrm{OHdG}$ adducts per $10^{5} \mathrm{dG}$ bases. The $8 \mathrm{OHdG}$ standard used throughout the study was prepared according to Degan et $a l^{31}$ and compared with an authentic $8 \mathrm{OHdG}$ sample kindly provided by Dr B N Ames. Coefficients of variation were always lower than $15 \%$.

\section{STATISTICS}

The data were examined using one way analysis of variance and Student's $t$ test, the Kruskal-Wallis $\mathrm{H}$ test for non-parametric data where appropriate (Kolmogorov-Smirnov), and linear regression analysis. Stepwise multiple regression analysis was also used by including the following variables: $80 \mathrm{HdG}$ DNA concentrations, TBARS tissue concentrations, gastric juice vitamin $\mathrm{C}$ concentrations, vitamin $\mathrm{C}$ intake, diagnosis (as a score: controls $=1$, chronic non-atrophic gastritis $=2$, chronic atrophic gastritis $=3$, gastric cancer $=4$ ), presence and extent of $H$ pylori infection, presence and extent of intestinal metaplasia, disease activity, age, cigarette consumption, and daily alcohol intake. The results were considered to be statistically significant when $\mathrm{p}$ was less than 0.05 .

\section{Results}

Figure 1 presents the concentrations of $8 \mathrm{OHdG}$ in gastric mucosal biopsy specimens from patients with different degrees of damage. By one way analysis of variance, the patients with chronic atrophic gastritis had significantly higher $8 \mathrm{OHdG}$ tissue concentrations $(\mathrm{p}=0.009)$. In particular, a significant difference was found between chronic active gastritis and controls $(p=0.003)$. The presence of mild dysplastic changes, evident in $12 / 41$ patients, did not correlate with any further significant increase in $8 \mathrm{OHdG}$ tissue concentrations (table 1). Patients with no or mild intestinal metaplasia had significantly lower concentrations of $8 \mathrm{OHdG}$ than patients with moderate or severe changes $(p=0.035$; table 1$)$. The highest concentrations of $8 \mathrm{OHdG}$ were observed (35.3 (31.6) adducts per $10^{5} \mathrm{dG}$ residues, $\mathrm{p}=0.039$ ) when patients presenting with chronic atrophic gastritis associated with high grade intestinal metaplasia were considered separately.
Table 18 8HdG tissue concentrations in patients with epithelial dysplasia or intestinal metaplasia

\begin{tabular}{ll}
\hline & $8 O H d G$ \\
\hline Chronic active gastritis & \\
With epithelial dysplasia (12) & $28.9(21.3)$ \\
No epithelial dysplasia (29) & $29.6(26.1)$ \\
Intestinal metaplasia & \\
$\quad$ No intestinal metaplasia (34) & $15.4(2.2)^{\star}$ \\
Mild intestinal metaplasia (21) & $16.5(7.8)^{\star}$ \\
Moderate/severe intestinal metaplasia (33) & $32.2(6.7)^{\star}$ \\
\hline Values are expressed as mean (SD) number of adducts/105 dG \\
residues. \\
${ }^{\star} \mathrm{p}=0.035$ by one-way ANOVA.
\end{tabular}

Table 2 presents the results with respect to disease activity and $H$ pylori infection. Patients with moderate or severe disease activity had significantly higher concentrations of oxidative DNA adducts $(\mathrm{p}=0.02)$. The same situation was observed with respect to severity of $H$ pylori infection - that is, patients with moderate or severe $H$ pylori infection had significantly higher $80 \mathrm{HdG}$ concentrations $(\mathrm{p}=0.001)$.

Only $13 / 88$ patients smoked, and only three of these smoked more than 10 cigarettes per day. Only 25 patients drank alcoholic beverages, and only nine of these misused alcohol (more than $60 \mathrm{~g}$ alcohol/day in men and more than $40 \mathrm{~g}$ in women). Neither smoking habit nor alcohol consumption correlated with any change in $8 \mathrm{OHdG}$ mucosal concentrations (21.6 (11.5) adducts per $10^{5} \mathrm{dG}$ residues in smokers versus 23.6 (23.4) in non-smokers, NS; 20.6 (19.4) in drinkers versus 24.6 (23.4) in non-drinkers). This analysis was based on the classification of any patient who smoked at all as a smoker and of any patient who drank any alcohol as a drinker, but no difference was observed, either for smoking or drinking, in the very small group of misusers (data not reported).

No significant difference was observed in TBARS concentrations in the four groups of patients (fig 1), nor was there any difference in patients with no, mild, moderate, or severe intestinal metaplasia (no or mild: 25.7 (4.4), moderate: 30.1 (5.5), severe: 25.4 (4.3) $\mathrm{nmol} / \mathrm{g}$ ). However, patients with high grade intestinal metaplasia (moderate and severe cases considered together) showed a trend towards higher TBARS concentrations (28.1 (12.8) versus $24.3(11.1) \mathrm{nmol} / \mathrm{g})$. Similarly, no difference in TBARS concentrations was detected in patients with no versus moderate or severe disease activity (20.8 (8.6) versus 26.0

Table 2 8OHdG tissue concentrations according to disease activity and $H$ pylori infection

\begin{tabular}{lc}
\hline & $8 O H d G$ \\
\hline Disease activity & \\
$\quad$ Absent (29) & $7.2(5.4)^{\star}$ \\
Moderate (28) & $17.2(4.6)^{\star}$ \\
Severe (31) & $25.6(24.4)^{\star}$ \\
H pylori infection & \\
Absent (44) & $17.3(14.2) \dagger$ \\
Moderate (10) & $19.4(13.0) \dagger$ \\
Severe (34) & $53.1(43.8) \dagger$ \\
\hline
\end{tabular}

Values expressed as mean (SD) number of adducts $/ 10^{5} \mathrm{dG}$ residues.

${ }^{\star} \mathrm{p}=0.02$ by Kruskal-Wallis

t $\mathrm{p}=0.001$ by one-way ANOVA. 
Table 3 Significant correlations among the studied variables in all 88 patients

\begin{tabular}{llllll}
\hline & Disease activity & Histology & Intestinal metaplasia & H pylori infection & Age \\
\hline Disease activity & - & $0.61(0.0002)$ & - & $0.73(0.00001)$ & $0.49(0.1)$ \\
Histology & $0.61(0.0002)$ & - & $0.86(0.00001)$ & $0.49(0.005)$ & $0.55(0.0007)$ \\
Intestinal metaplasia & - & $0.86(0.00001)$ & - & - & $0.49(0.02)$ \\
H pylori infection & $0.73(0.00001)$ & - & - & - & $0.41(0.03)$ \\
\hline
\end{tabular}

(12.9) and $26.8(12.3) \mathrm{nmol} / \mathrm{g}$, respectively) or in patients with no, moderate, or severe $H$ pylori infection (no: 23.5 (7.8), moderate: 29.4 (14.4), severe: 27.8 (8.8) nmol/g; NS). However, $H$ pylori positive patients had significantly higher TBARS concentrations overall (29.1 (13.4) versus $21.5(8.7) \mathrm{nmol} / \mathrm{g}, \mathrm{p}=0.04)$.

Gastric juice vitamin C concentrations were lower in patients with chronic atrophic gastritis (controls: 201.8 (153), chronic non-atrophic gastritis: 154.3 (33), chronic atrophic gastritis: 88.1 (21) $\mathrm{nmol} / 1 ; \mathrm{p}=0.04$, chronic atrophic gastritis versus chronic non-atrophic gastritis). Vitamin C intake was similar in the three groups (controls: 36.2 (11.4), chronic nonatrophic gastritis: 34.3 (16.5), chronic atrophic gastritis: $37.5(25.5) \mathrm{mg} /$ day). No correlation was detected between vitamin $\mathrm{C}$ intake (or smoking) and age.

Table 3 presents the correlation matrix of some of the variables introduced in the stepwise multiple regression analysis. As there was such a small number of smokers and drinkers, the variables smoking and drinking were not considered for this analysis. By linear regression analysis, significant correlations were observed between: $8 \mathrm{OHdG}$ concentrations and $H$ pylori infection; histological diagnosis and disease activity; intestinal metaplasia, age, and histological diagnosis; and $H$ pylori infection, age, histological diagnosis, and disease activity. In the analysis for prediction of the multiple logistic regression, $H$ pylori infection $(\mathrm{p}=0.008)$ was selected as a single independent predictor of mucosal concentrations of $8 \mathrm{OHdG}$.

\section{Discussion}

8OHdG MUCOSAL CONCENTRATIONS

The importance of oxidative damage in chronic gastritis, either correlated with $H$ pylori or not, has been confirmed in various studies. ${ }^{92324}$ As it is known that free radicals may also be involved in carcinogenesis, the above studies have posed the question whether the free radical production underlying all such changes is also a possible cause of the accumulation of oxidative DNA damage in chronic gastritis. The method adopted in this study ${ }^{30}$ enables determination of the concentrations of a single adduct that has a known mutagenic and carcinogenic potential, ${ }^{22}$ and is related to free radical mediated damage which may indeed increase concentrations of physiological production of oxidised DNA. ${ }^{32}$ It has indeed been shown that oxidative DNA damage is a continous and ubiquitous process resulting from the production of oxygen radicals due to the unavoidable error rate of electron addition to oxygen in the electron transport chain of mitochondria and other endogenous metabolic processes that utilise oxygen. ${ }^{16}$

The extent of DNA damage in the gastric mucosa had been investigated previously by using ${ }^{32} \mathrm{P}$ postlabelling ${ }^{33}$ or $\mathrm{O}-6$-methyl guanosine radioimmunoassay detection. ${ }^{34}$ These studies reported an increase in DNA damage, which failed to reach statistically significant concentrations, even in gastric cancer; the authors concluded that there was no direct indication of any relation between cancer risk and extent of DNA damage.

In our experience, there is a significant accumulation of oxidative DNA damage in patients with simple chronic gastritis; this is more clearly apparent in patients with gastric cancer precursors in the gastric mucosa, such as atrophic gastritis and intestinal metaplasia. To our mind, the difference between the presented data and the previously reported results is due to the method adopted, which specifically detected oxidative DNA lesions that may be more relevant to the type of damage peculiar to $H$ pylori mediated gastritis.

A question arises as to whether this damage is an early or late occurrence. As the development of precancerous lesions, ${ }^{35}$ such as dysplasia (which can progress to cancer even when it is low $\operatorname{grade}^{36}$ ), was not associated with any further increase in oxidative DNA damage, and the same was true for gastric cancer, this accumulation is presumably an early event. On the other hand, as it takes a long time for chronic atrophic gastritis to develop in the stomach, this accumulation might equally be seen as a late event. The development of this DNA damage in the gastric mucosa seems to occur later than in the case of chronic liver disease, in which a significant accumulation can be detected in patients without cirrhosis. ${ }^{37}$ However, even low amounts of DNA oxidative damage may be important, as high concentrations can lead to cell death while low concentrations can easily be repaired. ${ }^{38}$

All the variables indicating more severe damage-presence of extensive intestinal metaplasia, severe disease activity, or intensive $H$ pylori colonisation of the mucosal surfacewere associated with a further increase in concentrations of $8 \mathrm{OHdG}$ in the gastric mucosa. This was to be expected, at least for disease activity and $H$ pylori infection, ${ }^{39}$ as free radical production is due to polymorphonuclear cell activation and recruitment, ${ }^{12}$ which are both increased in the presence of $\mathrm{H}$ pylori and more severe gastritis. An intriguing finding was that a greater amount of DNA damage was also detectable in patients with diffuse and severe intestinal metaplasia, which can also be regarded as a precancerous condition. Moreover, patients with chronic atrophic gastritis and 
severe intestinal metaplasia were characterised by very high $8 \mathrm{OHdG}$ concentrations. It is possible that, beyond the hypothesis of an accumulation of damage due to $8 \mathrm{OHdG}$ formation overwhelming the capacity for repair, the increased extent of DNA damage found in specific subgroups of patients could also be due to the presence of cagA/vacA producing $H$ pylori strains which, at least in some studies, ${ }^{40-42}$ have been found to be associated with more severe damage and a higher risk of gastric cancer.

Finally, by regression analysis, the accumulation of oxidative DNA damage was found to be unrelated to age (though controls had both a lower age and lower $8 \mathrm{OHdG}$ concentrations), or to smoking and drinking habits. Both linear and non-linear correlations of $8 \mathrm{OHdG}$ tissue concentrations with age have been reported. ${ }^{43}{ }^{44}$ The lack of any such correlation in this study might be explained by the presence of a relatively small group of younger subjects in the sample, or by the fact that the study contained not "healthy" controls, but patients, defined as unaffected controls, with a chronic pathology clearly related to free radical production. Any correlation with age is therefore probably masked by the more relevant influence of damage.

TBARS MUCOSAL CONCENTRATIONS AND GASTRIC JUICE VITAMIN C

TBARS mucosal concentrations proved a less accurate indicator of free radical mediated tissue damage. Concentrations were higher in chronic atrophic gastritis, but not significantly so, and the only parameter that was significantly correlated with a clear cut increase in TBARS was the presence of $H$ pylori infection. These results provide only partial confirmation of previously published findings. ${ }^{23}{ }^{24}$ No correlation was detectable between TBARS and $8 \mathrm{OHdG}$ concentrations. This suggests that the two parameters probably indicate different pathways of damage. Furthermore, damage to DNA, lipids, proteins, or carbohydrates depends on the type of cell under oxidative stress and on the mechanisms involved..$^{45}$

Gastric juice vitamin C concentrations were relatively low in chronic atrophic gastritis patients with a comparable vitamin $\mathrm{C}$ intake, as in several previous studies, ${ }^{23246}$ and they showed no correlation with either TBARS or $8 \mathrm{OHdG}$ concentrations. These findings are in partial conflict with results previously reported by Dyke et al, ${ }^{47}$ in whose study vitamin C supplementation led to a reduction in gastric mucosal DNA damage. However, the type of DNA adducts determined in their study by the ${ }^{32} \mathrm{P}$ postlabelling method was different, as they formed following exposure to different types of genotoxic chemicals. The authors also found no correlation between baseline vitamin $\mathrm{C}$ in the gastric juice and DNA adduct concentrations, and this confirms our own data. These observations imply that gastric juice vitamin C concentrations may vary in relation to different factors and that a specific correlation with the extent of mucosal DNA oxidative damage cannot be confirmed.
A number of significant correlations were found in our study, generally concerning the degree of histological damage, in terms of chronic atrophic gastritis and intestinal metaplasia, the patients' age, and the presence of $H$ pylori infection. These correlations were, to some extent, expected. More interesting was the finding that, in stepwise multiple linear regression analysis (which enables the identification of single or paired independent predictors for a given variable), the presence and extent of $H$ pylori infection emerged as a single independent predictor of gastric mucosal concentrations of $8 \mathrm{OHdG}$, with a very high degree of significance. This indicates that $H$ pylori infection is the most important factor in causing accumulation of oxidative DNA mutations. As $H$ pylor infection is also correlated with an increase in the proliferative activity of the gastric epithelia, ${ }^{48}$ it can be concluded that the bacterium may act as both a potential initiator and as a promoter of gastric carcinogenesis.

\section{CONCLUSIONS}

In conclusion, this study shows that: specific oxidative DNA damage is detectable in the gastric mucosa in chronic gastritis. This damage correlates with the development of precancerous mucosal changes and specifically with the onset of atrophy and extensive intestinal metaplasia. $H$ pylori infection is the single most important factor in determining the concentrations of $8 \mathrm{OHdG}$, thus indicating that the chronic inflammatory reaction caused by the bacterium is directly involved in gastric carcinogenesis through its potential for causing excess production of reactive oxygen species and consequent mutagenic and carcinogenic changes in DNA.

This work was carried out under the auspices of the R Farini Foundation for Research in Gastroenterology and was supported in part by a grant from the Italian National Research ported in part
Council (CNR)

1 Correa P. Human gastric carcinogenesis: a multistep and multifactorial process. Cancer Res 1992;52:6735-40.

2 Forman D, Newell DG, Fullerton F, et al. Association between infection with Helicobacter pylori and risk of gastric cancer: evidence from a prospective investigation. BMF 1991;302:1302-5

3 Parsonnet J, Friedman GD, Vandersteen DP, et al. Helicobacter pylori infection and risk of gastric carcinoma. N Engl f Med 1991;325:1127-31.

4 Nomura A, Stemmermann GN, Chyou PH, et al. Helicobacter pylori infection and gastric carcinoma among Japanese Americans in Hawaii. N Engl f Med 1991;325:1132-6.

5 Forman D, Webb P, Newell D, et al. An international association between Helicobacter pylori infection and gastric cancer. The Eurogast Study Group. Lancet 1993;341: 1359-62.

6 IARC Monographs on the evaluation of carcinogenic risks to humans. Infection with Helicobacter pylori. Vol 61 . to humans. Infection with Helicobacter pylori. Vol 61 . 177-40.

7 Langton SR, Cesareo SD. Helicobacter pylori associated phospholipase A2 activity: a factor in peptic ulcer production? f Clin Pathol 1992;45:221-4.

8 Rautelin $\mathrm{H}$, Blomberg B, Fredlund $\mathrm{H}$, et al. Incidence of Helicobacter pylori strains activating neutrophils in patients with peptic ulcer disease. Gut 1993;34:599-603.

9 Davies GR, Simmonds NJ, Stevens TRJ, et al. Helicobacter pylori stimulates antral mucosal reactive oxygen metabolite production in vivo. Gut 1994;35:179-85.

10 Mooney C, Keenan J, Munster D, et al. Neutrophil activation by Helicobacter pylori. Gut 1991;32:853-7.

11 Basaga HS. Biochemical aspects of free radicals. Biochem Cell Biol 1990;68:989-98.

12 Weitzman SA, Gordon LI. Inflammation and cancer: role of phagocyte-generated oxidants in carcinogenesis. Blood $1990 ; 76: 655-63$

13 de Groot H. Reactive oxygen species in tissue injury. Hepatogastroenterology 1994;41:328-32. 
14 Adelman R, Saul RL, Ames BN. Oxidative damage to DNA: relation to species metabolic rate and life span. Proc Natl relation to species metabolic rate
Acad Sci USA 1988;85:2706-18.

15 Crawford D, Cerutti P. Expression of oxidant stress-related genes in tumor promotion of mouse epidermal cells JB6. In: Nygaard O, Simic M, Cerutti P, eds. Anticarcinogenesis and radiation protection. New York: Plenum Press, 1989: $183-90$.

16 Ames BN. Mutagenesis and carcinogenesis: endogenous and exogenous factors. Environ Mol Mutagen 1989; 14(suppl 16):66-77.

17 Troll W, Wiesner R. The role of oxygen radicals as a possible mechanism of tumor promotion. Annu Rev Pharmacol Toxicol 1985;25:509-28.

18 Cathcart R, Schwiers E, Saul RL, et al. Thymine glycol and thymidine glycol in human and rat urine: a possible assay for oxidative DNA damage. Proc Natl Acad Sci USA 1984; 81:5633-7.

19 Hollstein MC, Brooks P, Linn S, et al. Hydroxymethyluracil DNA glycosylase in mammalian cells. Proc Natl Acad Sci DNA glycosylase in

20 Shigenaga MK, Gimeno CJ, Ames BN. Urinary 8-hydroxy2'-deoxyguanosine as a biomarker of in vivo oxidative DNA damage. Proc Natl Acad Sci

21 Kasai H, Nishimura S. Formation of 8-hydroxydeoxyguanosine in DNA by oxygen radicals and its biological
significance. In: Sies H, ed. Oxidative stress: oxidants and antioxidants. London: Academic Press, 1991:99-106.

22 Kuchino Y, Mori F, Kasai H, et al. Misreading of DNA templates containing 8-hydroxydeoxyguanosine at the modified base and at adjacent residues. Nature 1987;327:77-9.

23 Farinati F, Cardin R, Della Libera G, et al. Lipid peroxidation and anti-oxidant defence in human gastric mucosa: effect of Helicobacter pylori. Eur 7 Gastroenterol Hepatol 1993;5(suppl 2):S9-11.

24 Farinati F, Della Libera G, Cardin R, et al. Gastric antioxidant, nitrites, and mucosal lipoperoxidation in chronic gastritis and Helicobacter pylori infection. F Clin Gastroenterol 1996;22:275-81.

25 Bingham SA, Gill C, Welch A, et al. Comparison of dietary assessment methods in nutritional epidemiology: weighed records v. $24 \mathrm{~h}$ recalls, food-frequency questionnair
estimated-diet records. $B r \mathcal{F}$ Nutr 1994;72:619-43.

26 Price AB. The Sydney system. F Gastroenterol Hepatol 1991; 6:209-22.

27 Morson BC, Sobin LH, Grundmann E, et al. Precancerous conditions and epithelial dysplasia in the stomach. $\mathcal{F}$ Clin Pathol 1980;33:711 -21.

28 Sobala GM, Schorah CJ, Sanderson M, et al. Ascorbic acid in the human stomach. Gastroenterology 1989;97:357-63.

29 Masugi F, Nakamura T. Measurement of thiobarbituric acid value in liver homogenate solubilized with sodium dodecylsulphate, and variation of the values affected by vitamin $\mathrm{E}$ and drugs. Vitamins 1977;51:21-9.

30 Fraga CG, Shigenaga MK, Park JW, et al. Oxidative damage to DNA during aging: 8-hydroxy-2'-deoxyguanosine in rat organ DNA and urine. Proc Natl Acad Sci USA 1990;87: organ D D 7 .

31 Degan P, Shigenaga MK, Park EM, et al. Immunoaffinity isolation of urinary 8-hydroxy-2'-deoxyguanosine and 8-hydroxyguanine and quantitation of 8-hydroxyguanosine in DNA by polyclonal antibodies. Carcinogenesis 1991;12: 865-71.

32 Ames BN. Endogeneous oxidative DNA damage, aging, and cancer. Free Radic Res 1989;7:121-8.

33 Dyke GW, Craven JL, Hall R, et al. DNA damage as measured by ${ }^{32} \mathrm{P}$-postlabelling in normal and pre-malignant gastric mucosa. Cancer Lett 1994;77:45-50.

34 Hall CN, Badawi AF, O'Connor PJ, et al. The detection of alkylation damage in the DNA of human gastrointestinal tissues. Br F Cancer 1991;64:59-63.

35 Ming SC, Bajtai A, Correa P, et al. Gastric dysplasia. Significance and pathologic criteria. Cancer 1984;54:1794-801.

36 Rugge M, Farinati F, Baffa R, et al for the Interdisciplinary Group on Gastric Epithelial Dysplasia. Gastric epithelial dysplasia in the natural history of gastric cancer: a multicenter prospective follow-up study. Gastroenterology multicenter prospectiv

37 Farinati F, Cardin R, De Maria N, et al. Iron storage, lipid peroxidation and glutathione turnover in chronic anti-HCV positive hepatitis. $\mathcal{F}$ Hepatol 1995;22:449-56.

38 Halliwell B, Aruoma OI. DNA damage by oxygen-derived species. Its mechanism and measurement in mammalian systems. FEBS Lett 1991;281:9-19.

39 Baik Y-C, Youn H-S, Chung M-H, et al. Increased oxidative DNA damage in Helicobacter pylori-infected human gastric mucosa. Cancer Res 1996;56:1279-82.

40 Figura N, Crabtree JE. Vacuolating toxin of Helicobacter pylori. In: Hunt R, Tytgat G, eds. Helicobacter pylori. Basic mechanisms to clinical cure. Lancaster: Kluwer Academic Press, 1994:222-31.

41 Parsonnet J, Friedman GD, Orentreich N, et al. Infection with the type I phenotype of $\mathrm{H}$. pylori increases risk for gastric cancer independent of corpus atrophy [abstract]. Gastroenterology 1996;110:A221.

42 Queiroz DMM, Mendes EN, Rocha GA, et al. H. pylori strains possessing cagA and vacuolating cytotoxin producstrains possessing cagA and vacuolating cytotoxin produc-
ers are associated to both types of gastric carcinoma [abstract]. Gastroenterology 1996;110:A236.

43 Degan $\mathrm{P}$, Bonassi $\mathrm{S}$, De Caterina $\mathrm{M}$, et al In vivo accumulation of 8-hydroxy-2'-deoxyguanosine in DNA correlates with release of reactive oxygen species in Fanconi's with release of reactive oxygen species in
anaemia families. Carcinogenesis 1995;16:735-42.

44 Kaneko T, Tahara S, Matsuo M. Non-linear accumulation of 8-hydroxy-2'-deoxyguanosine, a marker of oxidized DNA damage, during aging. Mutat Res 1996;316:277-85.

45 Aruoma OI, Kaur H, Halliwell B. Oxygen free radicals and human diseases. F R Soc Health 1991;111:172-7.

46 Sobala GM, Pignatelli B, Schorah CJ, et al. Levels of nitrite, nitrate, $\mathrm{N}$-nitrosamine compounds, ascorbic acid and total bile acids in patients with and without precancerous conditions of the stomach. Carcinogenesis 1991;12:193-208.

47 Dyke GW, Craven JL, Hall R, et al. Effect of vitamin C supplementation on gastric mucosal DNA damage Carcinopenesis 1994;15:291-5.

48 Cahill RJ, Sant S, Beattie S, Hamilton $\mathrm{H}$, et al. Helicobacter pylori and increased epithelial cell proliferation: a risk factor for cancer. Eur $\mathcal{F}$ Gastroenterol Hepatol 1994;6:1123-8. 